J. Egypt. Soc. Parasitol. (JESP), 51(2), 2021: 313 - 322

(Online: 2090-2549)

\title{
VIABILITY OF HEPATIC HYDATID CYSTS IN RELATION TO THEIR PARASITOLOGICAL, MICROBIOLOGICAL AND RADIOLOGICAL FEATURES IN PATIENTS TREATED BY DIFFERENT PROTOCOLS
}

By

ENAS A. EL SAFTAWY ${ }^{1,2}$, AMANY A. ABD-ELAAL ${ }^{1,2}$, MANAL A. BADAWI ${ }^{3}$, AMR M. ABDELRAOUF ${ }^{4}$, EMAN Y. SHOEIB ${ }^{1}$, AMIRA MOHSEN ${ }^{5}$, AHMED A. AFIFE ${ }^{6}$, HAMIDA A. GOHAR ${ }^{7}$, and SAMAR S. ATTIA ${ }^{1,2^{\star}}$

Department of Medical Parasitology, Faculties of Medicine, Cairo University ${ }^{1}$ and, Armed Forces College of Medicine ${ }^{2}$, Cairo, Department of Pathology, National Research Institute ${ }^{3}$, Giza, Department of Tropical Medicine, National Hepatology and Tropical Medicine Research Institute ${ }^{4}$, Department of Community Medicine,

National Research Centre ${ }^{5}$, Egypt, Biomedical Sciences (BSc), University of Manchester ${ }^{6}$, UK, and Department of Medical Microbiology, Faculty of Medicine, Cairo University ${ }^{7}$, Egypt ( ${ }^{*}$ Correspondence: ssattia@kasralainy.edu.eg)

\section{Abstract}

Hydatid cyst disease is a parasitic infection caused by larval stage of Echinococcus granulosus affecting mainly the liver. Diagnosis of hepatic hydatidosis depends on clinical presentations, serological assays and radiological findings. The present study included 40 patients suffered from hepatic hydatid cysts. They were classified into 4 groups according to therapeutic protocols they received. All cases were subjected to serological assay, radiological examination to categorize cysts and open surgical intervention for treatment. Samples of hydatid fluid and cysts were examined regarding parasitological, morphometric and histopathological aspects. Viability of cyst contents was assessed using eosin stain. All samples were cultivated for microbiological assessment. Viability was $95-100 \%$ in GI (no previous treatment), $50-85 \%$ in GII, $25-45 \%$ in GIII (single PAIR technique and single Albendazole course) and $0-10 \%$ in GIV (repeated PAIR and medical treatment). Enterococci and Staphylococcus aureus were detected in one sample in GI and 8 samples in GIV respectively.

Key words: Egypt, Hydatid fluid, Viability, Protoscolices, Echinococcosis, Liver, Radiology.

\section{Introduction}

Echinococcosis/hydastidosis is the larval cestod of Echinococcus granulosus causes morbidity and mortality worldwide (WHO, 2017). Sheep raising countries showed the highest infection rate (van Cauteren et al, 2016), with zoonotic risk sheep-dog-man (Haridy et al, 2000). Also, man is infected by ingesting food, water or soil contaminated with stool from infected dogs or from fur contaminated (CDC, 2020). The liver is the first line of defense and the commonest affected organ (Zhang et al, 2003) with $75 \%$ of zoonotic cases (Kizilkaya et al, 2002). However, disseminated hydatidosis was reported in spinal cord (Mazyad et al, 1998), bone (Mazyad et al, 1999), spleen (Ramia-Angel et al, 2002), musculoskeletal (Vicidomini et al, 2007), pelvic bone (Liang et al, 2014), brain, cardiac muscle, peritoneum \& sub-cutis (Salamone et al, 2016), sub-retinal (Guo et al, 2017), lung (El-Sayed et al, 2020), and Kidney (George et al, 2020).

Mature hydatid cyst is formed of an inner germinal layer and outer acellular-laminated membrane with variable thickness, and increased diameter from 1 to $5 \mathrm{~cm}$ annually (Heath et al, 1994). Germinal layer gave the protoscolices that differentiated into adult worms in intestines of definitive hosts (Shaw et al, 2006). Protoscolices gave secondary hydatid cysts in the intermediate host after rupture of a primary one (Siracusano et al, 2012).

The main clinical picture of hepatic hydatidosis is upper right hypochondrial or epigastric pain with palpable abdominal mass on examination (Marti-Bonmati and Serrano, 1990). Obstructive jaundice may occur due to pressure of the growing cyst on bile duct (Atahan et al, 2011), hydatid cyst rup- 
ture causes severe allergic manifestations with a life threatened anaphylactic shock (Demircan et al, 2006).

Hepatic hydatidosis showed characteristic images (Moro et al, 2005) and were divided into: CL, CE1, CE2, CE3a, CE3b, CE4, \& CE5 types (Turgut et al, 2008). CE1 \& CE2 cysts were active \& fertile with viable protoscolices, CE3a \& CE3b cysts were in a transitional stage with compromised integrity of cyst, but CE4 \& CE5 cysts were inactive with degenerative changes (Rinaldi et al, 2014). The hydatid cyst wall was double echogenic lines separated by a hypo-echogenic layer of three cyst wall layers (Moguillanski et al, 1999; Mouhsine et al, 2014). Hydatid sands were multiple echogenic foci within the lesion, a sign called the snowstorm sign (Gharbi et al, 1981; Polat et al, 2005).

Hydatid cyst fluid (HCF) gave the parasite nutrients and biochemical structure reflecting metabolic functions (Li et al, 1985), as carbohydrate and protein control the cyst vitality (El Saftawy et al, 2017).

The present study aimed to evaluate cystic viability in relation to different clinical, parasitological and radiological features.

Ethical considerations: Protocol was approved, by Parasitology Department, and Ethical Committee, Deanship of Higher Education and Scientific Researches, Faculty of Medicine, Cairo University, as well as the Scientific Committee of National Institute of Hepatology, Cairo, Egypt.

\section{Patients and Methods}

This cross sectional study was carried out on patients attended Surgery Department, National Hepatology and Tropical Medicine Research Institute, Cairo from April 2015 to October 2016. A total of 40 cases (males $22(55 \%) \&$ females $18(45 \%)$ aged from 22 to 55 years) were presented with clinical manifestations suggestive of hepatic hydatidosis. They were diagnosis by parasitological, radiological and histopathological results. The informed written consents were obtained from all the patients.
Patients were classified into 4 groups according to the therapeutic protocols they previously received: GI: 2 cases $(4 \%)$ without medical treatment and diagnosed by surgical intervention. GII: 5 cases treated with a single Albendazole ${ }^{\circledR}$ course. GIII: 11 cases with recurred hydatid cyst treated by single PAIR technique combined with Albendazole. GIV: 22 cases with recurred hydatid cyst treated by repeated PAIR techniques combined with Albendazole

Patients were subjected to: 1- Serological assay for IHAT anti-hydatid antibody titer using a commercially kit (Fumouze ${ }^{\circledR}$ Microbiol, France) according to manufacturers' instructions. 2-Radiological examination: Echogenicity of cysts were assessed after WHO classification based on the presence of hydatid sand and calcifications, internal septa and daughter cysts. 3- Therapeutic intervention: After clinical and radiological evaluation, all cases were eligible for surgical intervention as the treatment of choice (Abdel Raouf et al, 2016). Fresh hydatid cyst fluids (HCF) were obtained during the surgical resection and transferred to sterile labeled centrifuge tubes. The samples were immediately examined and preserved in formalin $10 \%$ deep freeze at $-4^{\circ} \mathrm{C}$. 4- Parasitological examination: After HCF centrifugation, sediment was collected for smear examination and another part was preserved in normal saline $(0.85)$ as $4: 1$ dilution for later processing. The wet mounts were examined for protoscolices' vitality, shape, motility, and status whether evaginated or invaginated (Clavel et al, 1999). Vitality assessment was done using 0.1 eosin stain. Live protoscolices were not stained, but dead ones were stained due to changes in osmo-regulatory mechanisms, and viability was calculated (Younes et al, 2011). 5- Histopathological examination: Paraffin sections were prepared and stained with hematoxylin and eosin for microscopic examination and photographed. Length $\&$ width of protoscolices were measured by an ocular micrometer calibrated on stage micrometer. 
Culture and sensitivity: HCF from each patient was cultured onto the Petri dishes at $37^{\circ} \mathrm{C}$ incubator for 24 hours and examined with bacterial growth. Samples showing positive bacterial growth were subjected to species isolated and sensitivity tests.

Statistical analysis: Data were analyzed using Statistical Package for the Social Sciences (SPSS) version 16 for Windows (SPSS Inc., Chicago, IL, USA), as mean of quantitative variables and percentages. $\mathrm{Nu}$ merical data were expressed as mean and standard deviation or median and range as appropriate. Qualitative data were expressed as frequency and percentage. Chisquare test (Fishers exact test) examined the relation between qualitative variables. For quantitative data, comparison between two groups was done using Mann-Whitney test (non-parametric t-test). Comparison between groups was done using Kruskal-Wallis test (non-parametric ANOVA), and then post-Hoc "Schefe test" on variable rank. $\mathrm{P}$ value $<0.0001$ was considered significant.

\section{Results}

The patients were 21 patients were from rural areas and 19 patients were from urban areas, $11(27.5 \%)$ patients had pet dogs and 29 cases $(72.5 \%)$ never dealt with dogs, without significant differences.

The clinical manifestations were abdominal fullness in 36(90\%), vague abdominal pain in 35(87.5\%), breathlessness in 35 $(87.5 \%)$, obstructive jaundice, biliary colic, $\&$ urticaria in $12(30 \%)$ and low grade fever in $9(22.5 \%)$.

WHO classification for radio-diagnosis of hepatic hydatidosis showed cases in GI were cystic lesion (CL) without pathognomonic findings related to hydatidosis. GII showed pathognomonic radiological findings CE1. Most of them were in GIII (9/11 cases) showed CE3 radiological findings while the last 2 showed typical features related to CE4 "ball of wool" sign indicative of degenerating membranes. These findings were reported as well in 14/22 cases in GIV; the last 8 cases showed signs of ca- lcifications CE5 (Fig. $1 \&$ 2).

IHAT were positive in $26 / 40(65 \%)$ cases, and 14 were negative $(35 \%)$. High positive titer of 640 or more were in 12 cases, 1 case in GI and 11 cases in GIV with P value $<0.001$ (Fig. 3a \& b).

The color of hydatid cyst fluid was translucent in 15 cases, reddish in 5 cases, greenish in 7 cases, whitish to yellowish in 10 cases, clear in 18 cases and turbid in 22 cases (Fig. 4).

Protoscolices were detected in 38/40 HCF samples (in GI, GII, \& GIII), but just hooks were identified in 2 HCF samples of GIV.

Viable protoscolices were well-constructed contour, intact tegument, invaginated head, and well-arranged hooks and full of refractile calcareous corpuscles (Fig. 5A \& B). Non-viable protoscolices showed different features, mainly affected suckers and rostellar regions, as tegmental destruction or fragmentation and hooklets' distortion. Complete protoscolices damage was in hydatid fluid samples of GIV, but in GII \& GIII there were less viability and protoscolices without complete damage. Correlation of protoscolices viability to cyst radiological grades showed normality in two cases of CE 1 \& CE 3 (one therapy course) evident only after eosin stain (Fig. 5D \& E). Complete damage was in HCF samples of CE4 \& CE5. Viability was 95 to $100 \%$ in CL ( 2 cases), 50 to $85 \%$ in CE1 (5 cases), 25 to $45 \%$ in CE 3 (9 cases), CE4 (16) \& 0$10 \%$ in CE 5 ( 8 cases). Other cellular structures significantly increased in CE4 \& CE5 (Fig. 5C). After eosin staining, viability were 95 to $100 \%$ in GI ( 2 cases), 55 to $85 \%$ in GII ( 5 cases), 25 to $50 \%$ in GIII ( 11 cases) and $0-10 \%$ in GIV (22 cases).

Scolices motility: Microscopically motility was in $1 / 40 \mathrm{HCF}$ samples within $4 \mathrm{hrs}$. Scolices became evaginated with prominent rostellum and suckers as active movement with flexible necks full of refractile calculus corpuscles (Fig. 6). Active rostellum and suckers movement was up-down, circular and oscillatory processes exerted 
by body related to neck.

As to width and length of protoscolices, the laminated layer \& germinal layer were $76.66 \pm 3.5 \mathrm{um}, 110 \pm 8.6 \mathrm{um} \& 675 \pm 35.3 \mathrm{um}$ Table 1: Measurement of different structures

\begin{tabular}{|c|c|c|}
\hline \multirow[t]{2}{*}{ Variants } & & \\
\hline & CL & CE1 \\
\hline Scolex width & $76.6 \pm 3.5$ & $70 \pm 1.7$ \\
\hline Scolex length & $110 \pm 8.6$ & $90 \pm 12.74$ \\
\hline Laminated layer & $675 \pm 35.3$ & $453.3 \pm 116$ \\
\hline Germinal layer & $18.26 \pm 8.3$ & $16.6 \pm 5.7$ \\
\hline
\end{tabular}

Histologically, the stained laminated and germinal layers removed after surgery was exa-mined. Viable cysts were in GI and some samples of G II, laminated layer compact well organized hyaline layer (Fig. $7 \& 8$ ). Non-viable cystic lesions were in GIV, laminated layer showed variable features reflected the non-viability status as disruption and disorganization (Fig. 7). Necrosis with detachment of the germinal layer from the laminated layer was in all cases of GIV.

Microbiological examination showed no growth of anaerobic bacteria in all samples. Aerobic bacterial infections (Enterococci and Staphylococcus aureus) were in one sample in GI and 8 samples in GIV respectively. Both the Enterococci and Staphylococcus aureus were detected in 4 samples in CE4 \& 3 samples in CE5 respectively (Fig. 8), with chiefly moderate but only one CE4 sample showed heavy growth.

\section{Discussion}

Diagnosis relies on history taking, physical examination, serological assays and radiological findings and confirmed by microscopic examination of the cyst content (Zhang et al, 2012). Classification of cyst stages based on radiological findings helps in selecting the proper management (Pedrosa et al, 2000).

In the present study, the highest viability (50\%-85\%) was reported in cases who received one course of Albendazole. In these patients, cysts were radiologically classified as CE1. Chemotherapeutics commonly used for human hydatidosis hypothetically inhibit the assembly of tubulin into micro- respectively ( $\mathrm{P} \leq 0.05)$. The $\mathrm{CE} 5$ cysts were the lowest viability ones $41.24 \pm 4.56 \mathrm{um}$, $55.55 \pm 8.22$ um \& 91.90 \pm 17.12 um respectively (Tab.1).

of parasite versus related radiological grade Radiological grade

\begin{tabular}{|c|c|c|}
\hline $59.4 \pm 1.9$ & $49.3 \pm 3.2$ & $41.2 \pm 4.5$ \\
\hline $65.6 \pm 5.6$ & $60 \pm 3.2$ & $55.5 \pm 8.2$ \\
\hline $195.4 \pm 45.6$ & $150 \pm 20.6$ & $91.9 \pm 17.1$ \\
\hline $10.4 \pm 3.5$ & $6.7 \pm 2.1$ & $4.4 \pm 3.6$ \\
\hline
\end{tabular}

tubules and impair glucose absorption through the hydatid cyst wall. This action caused degeneration of the endoplasmic reticulum and mitochondria of the germinal layer and cellular death (Schantz et al, 1982; Todorov et al, 1992). The efficiency of medical treatment depends on the capacity of the drug to act on the germinal layer and protoscolices of the hydatid cyst at adequate concentrations for sufficient periods (Manouras et al, 2007). But, vitality was significantly minimized when combined therapy was used as reported by Turkcapar et al. (1997) and Senyüz et al. (2001) who recommended such combination to reduce the postoperative recurrence.

In the present study, the non-viable invaginated protoscolices were significantly smaller in size than the viable ones. The diminution in size might be attributed to the degenerative effect of the combined repeated therapy on the components of hydatid cysts and subsequently changed their measurements.

The reduction in size of germinal layer in non-viable cysts might be attributed to the attenuated activity of the germinal layer as a result of effective therapy (Stettler et al., 2004). In viable hydatid cyst, the laminated layer was significantly thicker due to the presence of a highly active germinal layer that progressively deposited a thick laminated layer (Alvaro et al, 2011). In the present study, protoscolices, germinal layer and laminated layer were significantly reduced in the later radiological grades as compared to CL \& CE1 cases. The movement in the free scolices was explained by 
the presence of muscle fibers along the anterior/ posterior rostellum axis (Martinez et $a l, 2005)$ and muscle bundles in suckers region (Galindo et al, 2008). These muscle fibers aid in the extension and retraction movements of the hooks when the protoscolex became fixed to the host tissues (Swiderski, 1981; Galindo et al, 2008). Other factors involved in scolices movement included CNS \& genes encoded for enzymes receptors and transporters needed for synthesis and serotonin transporting (neurotransmitter) in the parasites (Li et al, 2013).

In the present study, the IHAT showed that $65 \%$ were negative and $35 \%$ were positive. This more or less agreed with Kiliç et al. (2007). IHAT was negative in many radiologically cases categorized as CL \& $\mathrm{CE} 1$. These high negative results may reflect the efficiency of the parasite to sequestrate its antigen away from the host immune system (Lorenzo et al, 2005). Hydatid cysts have two capsules surrounded by a third host derived fibrous capsule, which probably protect the parasite from immune attacks (Zhang et al, 2003). The results of serological examinations for specific antibodies should be constantly linked to other diagnostic parameters as negative serological tests do not exclude hydatidosis (Carmena et al, 2006). Higher positive results were obtained in cases radiologically classified as CE3 \& CE4, but declined in grade CE5, the degenerative form of the parasite. In Egypt, many serologic techniques were used for hydatidosis; as IHA, IFA, ELISA, CCLE, but the ELISA sensitivity and specificity were $96.7 \%$ \& $97.5 \%$ respectively (El Shazly et al, 2010). Also, dot-ELISA was more acceptable with higher sensitivity, simple and commercial availability (Abou-Elhakam et al, 2016).

In the present study, culture and sensitivity of hydatid cyst obtained from the cases, gave either no growth or Staphylococcus aureus. Two main routes for bacterial infection in hydatid disease were the biliary communication and percutaneous- aspiration-injection-re-aspiration or PAIR technique (Agarwal et al, 2000; Celik et al, 2000). In PAIR technique, bacteria that colonize the skin represent the commonest source of the bacterial super-infection (Picard et al, 2003). The commonest isolated bacteria in infected hydatidosis were coagulase positive \& coagulase-negative Staphylococci, Escherichia coli, Klebsiella pneumonia, Proteus mirabilis, Enterobacter aerogenes, Pseudomonas aeroginosa and/or Edwardsiella tarda (Fallah et al, 2014).

\section{Conclusion}

Hepatic hydatidosis is a risky health problem worldwide. Avoiding street dogs and periodical examination and treatment of pet ones, as well as handwashing with soap \& warm water after handling dogs is a must.

Hydatidosis required interpretation of clinical, parasitological, serological and radiological diagnosis. The hydatid cysts viability varied significantly among cases given different therapeutic protocols with the least one among those exposed to repeated albendazole and underwent repeated PAIR technique. Viability of cysts was significantly related to radiological grading of cyst.

Conflict of interest: The authors declared that they had neither conflict of interest nor received fund.

Authors' contributions: All the authors equally contributed in this study

\section{References}

Abdel Raouf, A, Boraii, S, Elgohary, H, Mogahed, M, Elkholy, A, et al, 2016: Evaluation of packing the residual cavity after total or partial cyst resection in management of hepatic hydatid cystic disease. J. Egypt. Soc. Parasitol. 46, 2:453-60.

Abou-Elhakam, HM, Farid, AA, Mahana, N A, Bauiomy, IR, Elameer, AM, 2016: DOTELISA as a field test for hydatid diagnosis. J. Egypt. Soc. Parasitol. 46, 2:441-52.

Agarwal, R, Ayyagari, A, Yadav, VB, Pras ad, KN, Saraswat, VA, 2000: Infection of hepatic hydatid cyst with Yersinia enterocolitica. Trans. R. Soc. Trop. Med. Hyg. 94, 4:404-9.

Aktan AO, Yalin RA, Yeğen CY, Okboy N, 
1993: Surgical treatment of hepatic hydatid cysts. Acta Chirur. Belg. 93, 4:151-3.

Akyildiz, HY, Akcan, A, Karahan, I, Kucuk, C, Sözüer, E, et al, 2009: Recurrent liver hydatid disease: when does it become symptomatic and how does one diagnose it? Clin. Imag. 33:55-8.

Alvaro, D, Casaravilla, C, Irigo'́n, F, Lin, G, Previato, J, Ferreir, F, 2011: Understanding the laminated layer of larval Echinococcus structure. Trends Parasitol. 27, 5: 204-13

Atahan, K, Küpeli, H, Deniz, M, Gür, S, Çökmez, A, et al, 2011: Can occult cystobiliary fistulas in hepatic hydatid disease be predicted before surgery. Int. J. Med. Sci. 8, 4:315-20.

Besim, H, Karayalcin, K, Hamamci, O, Gungor, C, Korkma, Z, 1998: Scolicidal agents in hydatid cyst surgery. HPB Surg. 10: 347-51.

Bresson-Hadni, SM, Liance, JP, Meyer, R, Houin, JL, Vuitton, DA, 1990: Cellular immunity in experimental Echinococcus multilocularis infection. II. Sequential and comparative phenotypic study of the periparasitic mononuclear cells in resistant and sensitive mice. Clin. Exp. Immunol. 82:378-83.

Carmena, D, Benito, A, Eraso, E, 2006: Antigens for the immunodiagnosis of Echinococcus granulosus infection: an update. Acta Trop. 98:74-86.

CDC, 2020: Parasites-Echinococcosis: Cystic Echinococcosis (CE) FAQs.

Celik, M, Senol, C, Keles, M, 2000: Surgical treatment of pulmonary hydatid disease in children: Report of 122 cases. J. Pediatr. Surg. 35: 1710-3.

Chen, YC, Yeh, TS, Tseng, SF, Lin, DY, 2002: Hepatic cyst with superinfection in the non-endemic area in Taiwan. Am. J. Trop. Med. Hyg. 67:524-7

Clavel, AM, Varea, O, Doiz, L, López, J, Quílez, FJ, et al, 1999: Visualization of hydatid eleme-nts: Comparison of several techniques. J. Clin. Microbiol. 37, 5:1561-3.

D' Amelio, R, De Rosa, F, Pontesilli, O, Dayal, R, Brighouse, G, et al, 1989: Hydatid disease: Analysis of parasite antigens in circulating immune complexes and in preformed hydatid antigen antibody complexes. J. Med. Microbiol. Immunol. 178:177-86.

Demircan, O, Baymus, M, Seydaoglu, G, Akinoglu, A, Sakman, G, 2006: Occult cystobiliary communication presenting as postoperative biliary leakage after hydatid liver surgery:
Are there significant preoperative clinical predictors? CMA Media Inc. Can. J. Surg. 49, 3: 177-84.

Diaz, A, Ferreira, AM, Nieto, A, 1995: Echinococcus granulosus: interaction with host complement in secondary infection in mice. Exp. Parasitol. 80:473-82.

Dixon, JB, 1997: Echinococcosis. Comp. Immunol. Microbiol. Infect. Dis. 20:87-94

El Saftawy, EA, Abd El-Aal, AA, Badawi, M, Attia, SS, Abdelraouf, A, et al, 2017: Research note. One minute, intraoperative assessment of the viability of hydatid cysts using a simple reagent strip test. Helminthologia 54, 2:157-64.

El-Sayed, YA, Ibrahim, EA, Morsy, TA, 2020: Peri-cystectomy versus cystotomy and enucleation of germinal layer by tissue spearing technique for lung hydatid in Egypt. J. Egypt. Soc. Parasitol. 50, 3:494-503

El-Shazly, AM, Saad, RM, Belal, US, Sakr, T, Zakae, HA, 2010: Evaluation of ELISA and IHAT in serological diagnosis of proven cases of human hydatidosis. J. Egypt. Soc. Parasitol. 40, 2:531-8

Fallah, M, Kavand, A, Mashouf, RY, 2014: Infected hydatid cysts bacteria in slaughtered livestock and their effects on protoscolices degeneration. Jundishapur J. Microbiol. 7, 6:e1013523-8

Galindo, M, Schadebrodt, G, Galanti, N, 2008: Echinococcus granulosus: Cellular territories and morphological regions in mature protoscolices. J. Cell. Phys. 0216, 2:498-506.

Gharbi, HA, Hassine, W, Brauner, MW, Dupuch, KD, 1981: Ultrasound examination of the hydatic liver. Radiology, 139:459-63.

George, VP, Shanmugasamy, K, Srinivasan, S, Krishnamurthy, AV, Venkat, ATM, 2020: Hydatid cyst of kidney in a 60-year-old female: A rare case report. Indian J. Pathol. Microbiol. 63, 3:499-500.

Guo, C, Zhu, R, Qiu, J, Zhu, L, Yang, L, 2017: Subretinal echinococcosis: A case report. BMC Ophthalmol. 17, 1:185-9

Haridy, FM, Ibrahim, BB, Morsy, TA, 2000: Sheep-dog-man: The risk zoonotic cycle in hydatidosis J. Egypt. Soc. Parasitol. 30, 2: 423-9.

Heath, DD, Holcman, B, Shaw, RJ, 1994: Echinococcus granulosus: The mechanism of oncosphere lysis by sheep complement and antibody. J. Int. J. Parasitol. 24:929-35. Karaoğlanoğlu, M, Akinci, ÖF, Bozkurt, S, 
Deniz, Ş, Karataş, G, et al, 2004: Evaluating the effect of different pharmacological and chemical agents on the integrity of hydatid cyst membranes. Am. J. Roentgenol. 183:465-9.

Kiliç, S, Babür, C, Ozkan, A, 2007: Comparison of the results of indirect hemagglutination and ELISA methods for the cases prediagnosed as hydatid cyst disease. Mikrobiyol. Bul. 41, 4: 571-7.

Kizilkaya, E, Silit, E, Basekim, C, Karsli, AF, 2002: Hepatic, extrahepatic soft tissue and bone involvement in hydatid disease. Turk. J. Diag. Interven. Radiol. 8:101-4.

Li, ZH, Zhu, XQ, Sun, J, 1985: Basic composition analysis of cyst fluid in livestock. Chin. J. Vet. Sci. Technol. 11:36-7.

Li, J, Ju, Y, Wang, X, Zhang, Z, Junliang, L, et al, 2013: Analysis of the chemical components of hydatid fluid from Echinococcus granulosus. Rev. Soc. Bras. Med. Trop. 46, 5:60510.

Liang, Q, Wen, H, Yunus, A, Tian, Z, Jiang, F, et al, 2014: Treatment experience of pelvic bone hydatidosis. Int. J. Infect. Dis. 18:5761.

Lorenzo, C, Ferreira, HB, Monteiro, KM, Rosenzvit, M, Kamenetzky, L, et al, 2005: Comparative analysis of the diagnostic performance of six major Echinococcus granulosus antigens assessed in a double-blind randomized multicenter study. J. Clin. Microbiol. 43, 6: 2764-70.

Mackenzie, CD, 1984: Sequestration, beneficial to both host and parasite. Parasitology 88: 593-5.

Manouras, M, Genetzakis, EE, Lagoudianakis, A, Papadima, C, Triantafillou, PV, et al, 2007: Intact germinal layer of liver hydatid cysts removed after administration of albendazole. Neth. J. Med. 65:3-6.

Manterola, C, Vial, M, Pineda, V, Sanhueza, A, Barroso, M, 2005: Factors associated with morbidity in liver hydatid surgery. A. N. Z. J. Surg. 75, 10:889-92.

Marti-Bonmati, L, Menor Serrano, F, 1990: Complications of hepatic hydatid cysts: Ultrasound, computed tomography, and magnetic resonance diagnosis. J. Gastrointest. Radiol. 15:119-25.

Martinez, C, Paredes, R, Stock, R, Saralegui, A, Andreu, M, et al, 2005: Cellular organization and appearance of differentiated structures in developing stages of the parasitic plat- yhelminth Echinococcus granulosus. J. Cell. Biochem. 94:327-35.

Mazyad, MAM, Mostafa, MM, Morsy, TA, 1998: Spinal cord hydatid cysts in Egypt. J.

Egypt. Soc. Parasitol. 28, 3:655-8

Mazyad, MAM, Morsy, TA, Habib, KS, 1999: Vertebral unilocular hydatidosis in a shepherd and his wife. J. Egypt. Soc. Parasitol. 29, 2:547-50

Moguillanski, SJ, Gimenez, CR, Villavicencio, RL, 1999: Radiología de la hidatidosis abdominal. In: Stoopen ME, Kimura K, Ros P $\mathrm{R}$, eds. Radiología e imagen diagnóstica y terapeútica. J. Abdomen 2:47-72.

Moro, PL, Garcia, HH, Gonzales, AE, Bonilla, JJ, Verastegui, M, et al, 2005: Screening for cystic echinococcosis in an endemic region of Peru using portable ultrasonography and the enzyme-linked immunoelectrotransfer blot (EITB) assay. Parasitol. Res. 96, 4:242-6.

Morris, DL, 1989: Albendazole treatment of hydatid disease-follow up at 5 years. Trop. Doct. 19:179-80.

Morris, DL, Chinnery, JB, 1987: Penetration of Albendazole sulphoxide into hydatid cyst. Gut 28:75-80.

Mouhsine, A, Aitidir, B, Belkouch, A, Atmane, E, Rokhssi, R, 2014: Hydatid cyst of the liver revealed at the stage of superinfection, contribution of imaging: A case report. Inter. J. Med. Imag. 2, 6:138-40.

Pedrosa, I, Saiz, A, Arrazola, J, Ferreiros, J, Pedrosa, CS, 2000: Hydatid disease: radiologic and pathologic features and complications. J. Radiograph. 20, 3:795-817.

Picard, C, Puel, A, Bonnet, M, 2003: Pyogenic bacterial infections in humans with IRAK-4 de-ficiency. Science 299:2076-9.

Polat, FR, Polat, S, Sultanoglu, E, 2005: Laparoscopic treatment of hydatid cyst of the liver: A case report. J. Soc. Lap. Surg. 9:245-6.

Ramia-Angel, JM, Gasz, A, de la Plaza-Llamas, R, Quinones, J, Sancho, E, et al, 2011: Hidatidosis of the spleen. Pol. Przegl. Chir. 83, 5:271-5.

Rinaldi, F, De Silvestri, A, Tamarozzi, F, Cattaneo, F, Lissandrin, R, et al, 2014: Medical treatment versus Watch and Wait in the clinical management of CE3b echinococcal cysts of the liver. BMC Infect. Dis. 9:14:492.

Safioleas, M, Misiakos, E, Manti, C, Katsikas, D, Skalkeas, G, 1994: Diagnostic evaluation and surgical management of hydatid disease 
of the liver. World J. Surg. 18:859-65.

Salamone, G, Licari, L, Randisi, B, Falco, N, Tutino, R, et al, 2016: Uncommon localizations of hydatid cyst. Review of the literature.

G. Chir. 37, 4:180-5.

Schantz, PM, Van den Bossche, H, Eckert, J, 1982: Chemotherapy for larval echinococcosis in animals and humans: Report of a workshop. Z. Parasitenkd. 67, 1:5-26.

Senyuz, OF, Yesildag, E, Celayir, S, 2001: Albendazole therapy in the treatment of hydatid liver disease. Surg. Today, 3:1487-91.

Shaw, JM, Bornman, MB, Med, M, Glas, FR CS, Krige, MB, 2006: Hydatid disease of the liver. J. S. Afr. J. Surg. 44, 2:75-6.

Siracusano, A, Delunardo, F, Teggi, A, Ortona, E, 2012: Review article: Host-parasite relationship in cystic echinococcosis, an evolving story. J. Clin. Dev. Immunol. 2012:1-12.

Stettler, M, Rossignol, JF, Fink, R, 2004: Secondary and primary murine alveolar echinococcosis: combined albendazole/nitazoxanide chemotherapy exhibits profound anti-parasitic activity. Int. J. Parasitol. 34:615-24.

Swiderski, Z, 1981: Echinococcus granulosus: Hook-muscle systems and cellular organization of infective oncospheres. Int. J. Parasitol. 13: 289-99.

Todorov, T, Vutova, K, Mechkov, G, Georgiev, P, Petkov, D, Tonchev, Z, 1992: Chemotherapy of human cystic echinococcosis: Comparative efficacy of mebendazole and albendazole. Ann. Trop. Med. Parasitol. 86:59-66.

Turgut, AT, Akhan, O, Bhatt, S, Dogra, VS, 2008: Sonographic spectrum of hydatid dis ease. Ultrasound Q. 24, 1:17-29.

Turkcapar, AG, Ersoz, S, Gungor, C, Aydinuraz, K, Yerdel, MA, et al, 1997: Surgical treatment of hepatic hydatidosis combined with perioperative treatment with albendazole. Eur. J. Surg. 163:923-8.

Van Cauteren, D, Millon, L, de Valk, H, Grenouillet, F, 2016: Retrospective study of human cystic echinococcosis over the past decade in France, using a nationwide hospital medical information database. Parasitol. Res. 115:42615.

Vicidomini, S, Cancrini, G, Gabrielli, S, Naspetti, R, Bartoloni, A, 2007: Muscular cystic hydatidosis: A case report. BMC Infect Dis. Mar 30; 7:23. doi: 10.1186/1471-2334-7-23.

WHO, 2003: International classification of ultrasound images in cystic echinococcosis for application in clinical and field epidemiological settings. Acta Trop. 85, 2:253-61.

WHO, 2017: Neglected Tropical Diseases. Available from: http://www.who.int/neglected diseases/ diseases/en/

Younes, DA, Taher, GA, Ibraheim, ZZ, 2011: In vitro effects of some herbs used in Egyptian traditional medicine on viability of protoscolices of hydatid cysts. Kor. J. Parasitol. 49:255-63.

Zhang, W, Li, J, McManus, DP, 2003: Concepts in immunology and diagnosis of hydatid disease. Clin. Microbiol. Rev. 16, 1:18-36.

Zhang, W, Wen, J, Li, R, Lin, D, McManus, A, 2012: Immunology and immunodiagnosis of cystic echinococcosis: An update. Clin. Dev. Immunol. https://doi.org/10.1155/2012/101895

\section{Explanation of figures}

Fig. 1: Radiology. CL: Unilocular, cystic lesion (s) with uniform anechoic content, not clearly delimited by a hyperechoic rim (cyst wall not visible). CE1: Unilocular, simple cyst with uniform anechoic content defined by a hyperechoic rim (visible cyst wall). CE3: Unilocular cyst with daughter cysts. Anechoic content with detachment laminated membrane from cyst wall, visible as floating membrane or as water-lily sign. CE4: Heterogeneous echoic shadows (degenerative contents), with degenerating membranes.

Fig. 2: Bar chart representing past therapeutic intervention versus radiological hydatid cyst grades.

Fig. 3: Bar charts showed different radiological grades versus IHAT (a) and hydatid cyst viability (b).

Fig. 4: HCFs color. A: Translucent \& clear, B: Reddish \& clear, C: Greenish \& slightly turbid and D: Whitish to yellowish \& turbid.

Fig.5: Microscopic hydatid cyst. (A) Brood capsule, (B) invaginated viable protoscolices, (C) dagger shaped hooks, (D) non-viable protoscolices (pink in color), (E) degenerated protoscolices, (F) histopathological section showed compact thick laminated layer with protoscolices variable germinal layer sizes.

Fig. 6: Evaginated scolices with prominent suckers, rostellum and obvious corpuscles (black arrows).

Fig. 7: Histopathological findings in hydatid cyst sections stained with H \& E. (A): Compact thick laminated layer with variable scolices'

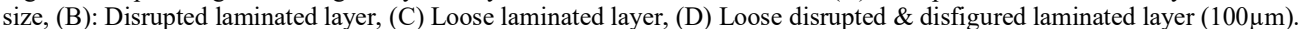

Fig. 8: Various thickness of germinal layer (arrow heads): (A) thick germinal layer in G1, (D) thinner germinal layer in G3. Nuclei (black arrows point) condensed in viable scolices (A \& B) and with scanty chromatin dots in non-viable scolices (C, D\& E) $(50 \mu \mathrm{m})$.

Fig. 9: A: Staphylococci aureus stained with Gram stain. B: Positive catalase test in Staphylococci infection. C: Mannitol salt agar to select and different growth medium. Gram + Staphylococcus ferment mannitol and medium turns yellow. D: Macconkey agar supported $S$ aureus growth. Colonies pale pink and opaque. 

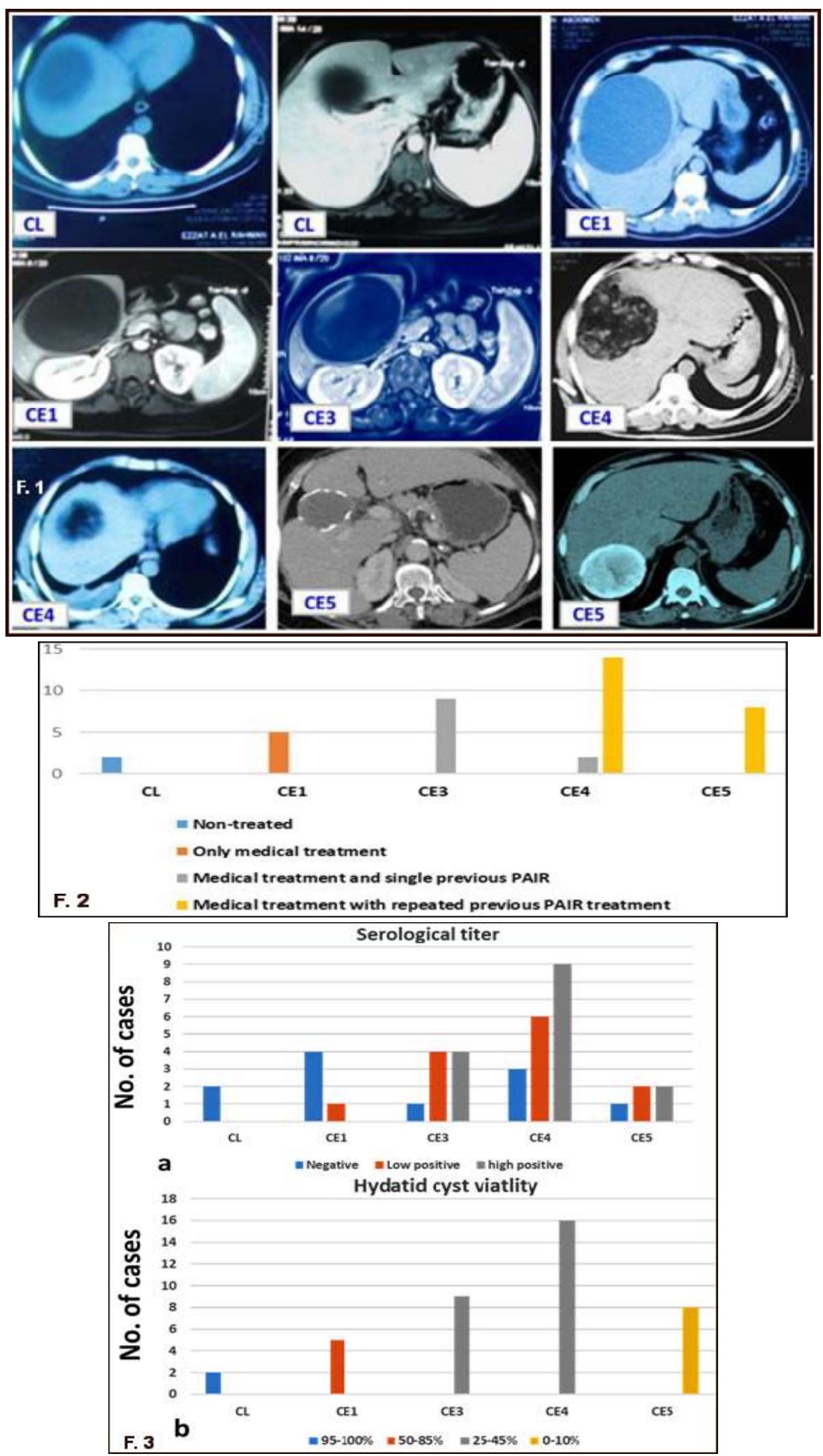


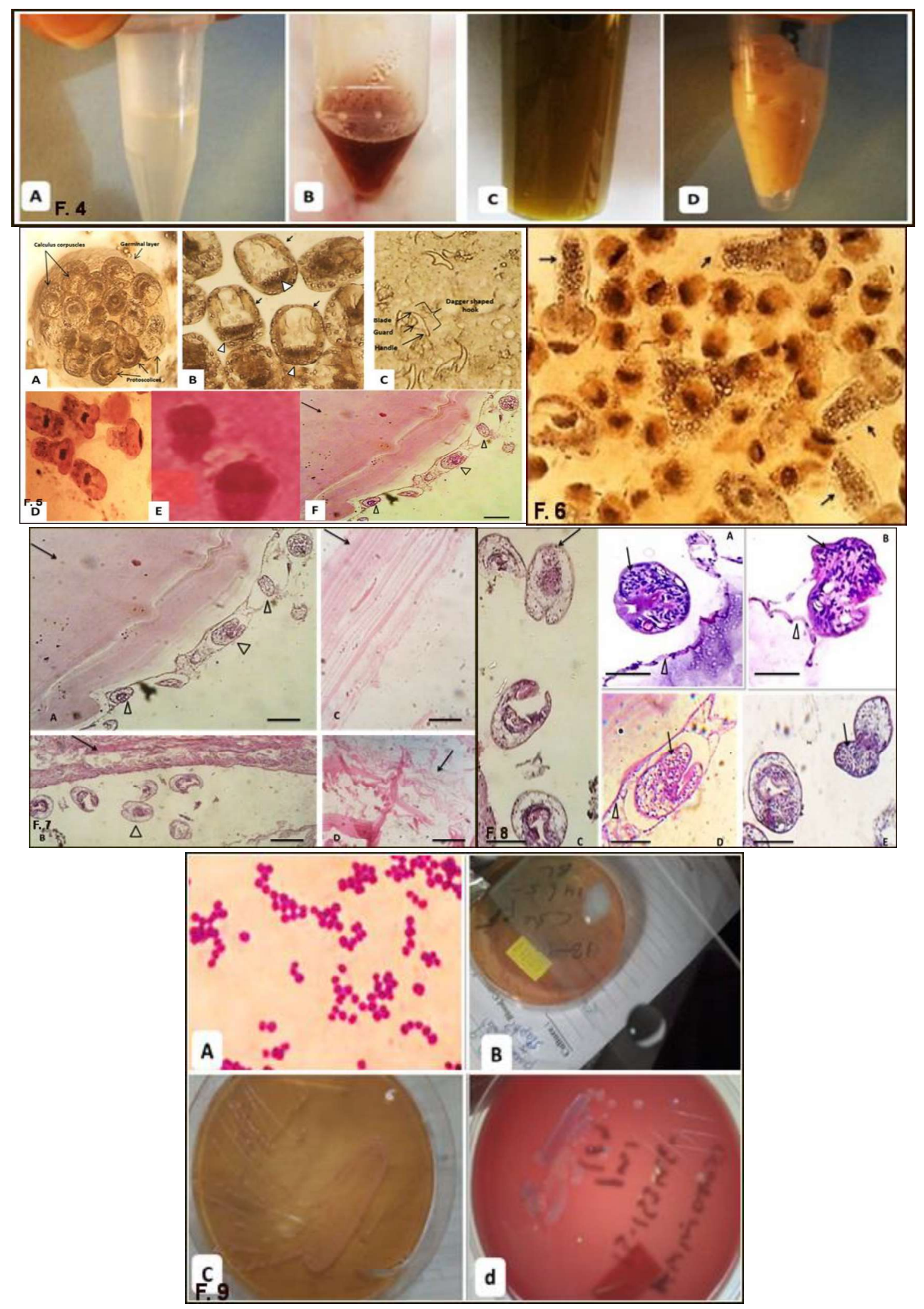

